\title{
ATP depletion induces translocation of STIM1 to puncta and formation of STIM1-ORAI1 clusters: translocation and re-translocation of STIM1 does not require ATP
}

\author{
Michael Chvanov • Ciara M. Walsh • Lee P. Haynes • \\ Svetlana G. Voronina • Gyorgy Lur • \\ Oleg V. Gerasimenko • Roger Barraclough • \\ Philip S. Rudland • Ole H. Petersen • \\ Robert D. Burgoyne • Alexei V. Tepikin
}

Received: 11 March 2008 / Accepted: 8 May 2008 / Published online: 10 June 2008

(C) The Author(s) 2008

\begin{abstract}
Depletion of the endoplasmic reticulum (ER) calcium store triggers translocation of stromal interacting molecule one (STIM1) to the sub-plasmalemmal region and formation of puncta-structures in which STIM1 interacts and activates calcium channels. ATP depletion induced the formation of STIM1 puncta in PANC1, RAMA37, and HeLa cells. The sequence of events triggered by inhibition of ATP production included a rapid decline of ATP, depletion of phosphatidylinositol 4,5-bisphosphate (PI $(4,5)$ $\mathrm{P}_{2}$ ) and a slow calcium leak from the ER followed by formation of STIM1 puncta. STIM1 puncta induced by ATP depletion were co-localized with clusters of ORAI1 channels. STIM1-ORAI1 clusters that developed as a result of ATP depletion were very poor mediators of $\mathrm{Ca}^{2+}$ influx. Re-translocation of STIM1 from puncta back to the ER was observed during total ATP depletion. We can therefore conclude that STIM1 translocation and re-translocation as well as formation of STIM1-ORAI1 clusters occur in an
\end{abstract}

Michael Chvanov and Ciara M. Walsh are considered as equal first authors.

M. Chvanov - C. M. Walsh - L. P. Haynes - S. G. Voronina •

G. Lur $\cdot$ O. V. Gerasimenko • O. H. Petersen • R. D. Burgoyne

A. V. Tepikin $(\triangle)$

Department of Physiology, School of Biomedical Sciences,

The University of Liverpool,

Crown Street,

Liverpool L69 3BX, UK

e-mail: a.tepikin@liv.ac.uk

R. Barraclough $\cdot$ P. S. Rudland

Molecular Medicine Research Group,

School of Biological Sciences, The University of Liverpool,

Liverpool L69 7ZB, UK
ATP-independent fashion and under conditions of $\mathrm{PI}(4,5) \mathrm{P}_{2}$ depletion.

Keywords STIM1 · ORAI1 · ATP · Store-operated calcium influx $\cdot \mathrm{Ca}^{2+}$ signals $\cdot$ ER calcium

$\begin{array}{ll}\text { Abbreviations } & \\ \text { Olig } & \text { Oligomycin } \\ \text { IA } & \text { Iodoacetate } \\ \text { 2DOG } & \text { 2-Deoxyglucose } \\ \text { Rot } & \text { Rotenone } \\ \text { STIM1 } & \text { Stromal interacting molecule one } \\ \text { Tg } & \text { Thapsigargin } \\ \text { TPEN } & N, N, N^{\prime}, N^{\prime} \text {-Tetrakis(2-pyridylmethyl)eth- } \\ & \text { ylenediamine } \\ \text { GFP-PH } & \text { Pleckstrin homology domain of plos- } \\ & \text { pholipase } \mathrm{C}_{\delta 1} \text { labeled with enhanced } \\ & \text { green fluorescent protein } \\ \text { PI(4)P } & \text { Phosphatidylinositol 4-phosphate } \\ \text { PI(4,5)P } 2 & \text { Phosphatidylinositol 4,5-bisphosphate } \\ \text { Wort } & \text { Wortmannin }\end{array}$

Introduction

The idea that the depletion of an intracellular calcium store activates a calcium influx pathway, which serves to replete the store was introduced in the 1980s [30,36]. The phenomenon was termed store-operated or capacitative calcium influx [30, 36]. Since that time, store-operated calcium influx has been characterised in numerous cell types [29, 30]. Considerable advances were made in the electrophysiological characteriza- 
tion of this process [17] (reviewed in [29]). A number of pathways involved in the regulation of store-operated calcium influx were described [2, 10,11, 16, 22, 41, 49], and some elegant theories were put forward to explain the phenomenon $[4,18]$. However, until very recently, neither the calcium sensor in the ER lumen nor the channel responsible for calcium influx were known. In the last few years, there has been remarkable progress in the characterization of storeoperated calcium influx. Stromal interacting molecule one (STIM1) was originally characterized as a plasma membrane protein with the properties of a tumor suppressor [26, 32, 39, 45]. Recently, two independent studies using a siRNA screen discovered and characterized the role of STIM1 in activation of store-operated calcium influx [20, 38]. It is now accepted that STIM1 is the calcium sensor in the ER, and translocation of STIM1 to the sub-plasmalemmal region followed by its interaction with calcium influx channels are the processes that mediate capacitative calcium influx. STIM2 could also play an important role particularly in establishing basal $\left[\mathrm{Ca}^{2+}\right]$ in ER and cytosol [5]. ORAI1 (also known as CRACM1) was found to function as an essential component of the $\mathrm{Ca}^{2+}$ entry channel $[8,35,44$, 48 , and the formation of the functional units of storeoperated $\mathrm{Ca}^{2+}$ entry was recently characterized by Luik et al. [21]. In their study, depletion of the ER calcium store induced translocation of STIM1 to sub-plasmalemmal puncta, which co-localized with ORAI1 clusters and regions of preferred calcium influx [21]. TRP channels [33] have been also considered as mediators of store-operated calcium influx [47]. The role of this channel type in store-operated calcium influx is currently debated [37].

The process by which STIM1 translocates to the plasma membrane is only partially characterized. The calcium sensor (the relatively low affinity EF hand domain) is localized to the part of the STIM1 molecule which projects into the ER lumen. After the decrease of ER calcium, STIM1 molecules form oligomers and thereafter move towards the plasma membrane to form sub-plasmalemmal puncta [19]. The observation that strands of ER could translocate towards the plasma membrane [46] suggests active (i.e. ATP-dependent) molecular motoring. The recently reported insertion of STIM1 into the plasma membrane by a specialized form of secretion [13] also suggests an ATP-dependent process (at least at the stage of vesicle recruitment [7]).

Sub-plasmalemmal mitochondria have been shown to effectively accumulate and regulate calcium entering the cell via various types of plasma membrane channels $[16$, $25,31]$. Several mechanisms of mitochondrial regulation of calcium influx have been described $[1,28,34]$.

A number of investigations indicated that ATP depletion resulted in the inhibition of store-operated calcium entry [3, 9, 23]. We confirmed this observation in the current study. We hypothesized that the reason for such inhibition could be suppression of an active transport process that transfers STIM1 to sub-plasmalemmal region, and we therefore decided to investigate the translocation of STIM1 under conditions of ATP depletion. To our surprise, ATP depletion actually induced STIM1 translocation and formation of subplasmalemmal puncta. This process was initiated and developed at very low ATP levels and substantially depleted $\mathrm{PI}(4,5) \mathrm{P}_{2}$. In the second part of the study we characterized the process of STIM1 re-translocation (restoration of diffuse STIM1 distribution after repletion of calcium stores) and observed that it can also occur in an ATP-independent fashion. Finally, we observed that ATP depletion triggers the formation of STIM1-ORAI1 clusters.

\section{Materials and methods}

\section{Plasmids}

STIM1-EYFP/mCherry-ORAI1 plasmid construction: HeLa cell total RNA was extracted from approximately $100 \times 10^{6}$ cells using Trizol reagent (Invitrogen, The Netherlands) and used as a template for reverse transcription using Improm-II reverse transcriptase (Promega, Southampton, UK) and oligo-dT $(15)$ priming. The resulting single stranded cDNA was then used as a template in PCR reactions to amplify full-length human STIM1 or ORAI1 using specific primers (below) containing restriction endonuclease sites to permit subsequent sub-cloning into the Cterminally tagging pEYFP-N1 vector (Clontech, Palo Alto, USA) or into the N-terminally tagging mCherry-C1 vector (gift from Roger Y. Tsien, University of California at San Diego) correspondingly. The primers for the STIM1 were based on the human sequence with GenBank accession number: NM_003156. The primers for ORAI1 were based on the human sequence with GenBank accession number: BC015369. All constructs were verified by automated sequencing in both directions (The Sequencing Service, University of Dundee, Dundee, UK).

Primers:

- STIM1 Sense (HindIII) 5'- ACTGAAGCTTATG GATGTATGCGTCCGTCTTGCC - 3'

- STIM1 Antisense (SacII) 5'- ACTGCCGCGGCTTCT TAAGAGGCTTCTTAAAG - 3'

- ORAI1 Sense (Xhol): 5'- ATATCTCGAGGAATG CATCCGGAGCCCGCCCCG - 3'

- ORAI1 Antisense (SacII): 5'- ATATCCGCGGC TAGGCATAGTGGCTGCCGGG - 3'.

The plasmid for ER targeted Cameleon (D1ER) was a gift from Roger Y. Tsien (University of California at San Diego). Properties of this probe for studies of ER calcium are described in [27]. 
Replication-deficient adenoviruses containing cytosolic luciferase (Ad-CMV-Luc) were purchased from Vector Biolabs (Philadelphia, PA, USA).

The PH domain of phospholipase $\mathrm{C}_{\delta 1}$ cloned into eCFP$\mathrm{C} 1$ was a gift from Dr. M. Katan (Imperial Cancer Research Fund, London, UK).

\section{Chemicals and reagents}

Cell culture reagents were purchased from Invitrogen (Paisley, UK), except for RPMI-1640 which was purchased from Cambrex (Nottingham, UK) and GeneJuice which was purchased from Merck Biosciences (Darmstadt, Germany). Thapsigargin and $N, N, N^{\prime}, N^{\prime}$-Tetrakis(2-pyridylmethyl)ethylenediamine (TPEN) were purchased from Calbiochem (San Diego, CA, US). Fura-2 AM and Fura Red AM were from Invitrogen/Molecular Probes. All other chemicals were purchased from Sigma (Gillingham, UK).

\section{Cell culture and transfection}

The RAMA37 cell line was maintained in Dulbecco's modified Eagle's medium (DMEM) supplemented with $10 \%$ fetal bovine serum (FBS), $1 \%$ Penicillin and Streptomycin, L-Glutamine, Hydrocortisone $(50 \mathrm{ng} / \mathrm{ml})$, and insulin $(50 \mathrm{ng} / \mathrm{ml})$. The PANC1 cell line was maintained in RPMI-1640 containing 10\% FBS and 1\% Penicillin and Streptomycin. HeLa cells were maintained in DMEM supplemented with $10 \%$ FBS, $1 \%$ Penicillin and Streptomycin and 1\% MEM nonessential amino acids.

Before transfection, cells were grown to $80-90 \%$ confluency in 35-mm Petri dishes with glass bottoms (MatTek, Ashland, MA, USA). Plasmids and transfection reagents were added directly to Petri dishes. Transfections of RAMA37 cell and PANC1 cells were carried out with 2 or $3 \mu \mathrm{g}$ of plasmid of interest and Lipofectamine 2000 according to the manufacturer's (Invitrogen) protocol. For transfection of HeLa cells, we used $3 \mu \mathrm{g}$ of plasmid(s) of interest supplemented with $8 \mu \mathrm{l}$ GeneJuice (Merck Biosciences). For simultaneous transfection with STIM1 and ORAI1 plasmids, $1.5 \mu \mathrm{g}$ of each plasmid DNA was mixed and supplemented with $8 \mu \mathrm{l}$ GeneJuice.

\section{Solutions}

The standard extracellular solution used during all experiments contained (in $\mathrm{mM}$ ): $\mathrm{NaCl} 140, \mathrm{KCl} 4.7, \mathrm{CaCl}_{2} 2$, $\mathrm{MgCl}_{2}$ 1.13, glucose 10, 4-(2-hydroxyethyl)-1-piperazineethanesulfonic acid 10 ( $\mathrm{pH}$ 7.3). To induce ATP depletion, cells were treated with a solution containing a combination of inhibitors $5 \mu \mathrm{M}$ Oligomycin (Olig) with $2 \mathrm{mM}$ Iodoacetate (IA) or $5 \mu \mathrm{M}$ Oligomycin with $10 \mathrm{mM}$ 2-deoxyD-glucose (2DOG). In some experiments, where indicated,
$\mathrm{CaCl}_{2}$ and glucose were omitted from the extracellular solution. All experiments were performed at room temperature. Cells were washed three times in standard extracellular solution and mounted in a perfusion chamber on the stage of an inverted microscope. During experiments, a gravity-fed perfusion system was used to exchange extracellular solution.

\section{Confocal microscopy}

Zeiss LSM 510 (Carl Zeiss, Jena, Germany) or Leica AOBS SP2 microscope (Leica Microsystems AG, Wetzlar, Germany) equipped with a $\times 63$ water immersion objective (N.A. 1.2) were used in our experiments. Images of STIM1-EYFP were obtained with $496 \mathrm{~nm}$ excitation light (488 nm in experiments conducted on Zeiss LSM 510) and emission fluorescence selected with a $505-550 \mathrm{~nm}$ bandpass filter. For excitation of ORAI1-mCherry $594 \mathrm{~nm}$ laser line was used. For simultaneous imaging of STIM1-EYFP and ORAI1-mCherry, we used 510-550 and 610-710 nm emission bandpasses, respectively. D1ER was imaged with $405 \mathrm{~nm}$ excitation light and 440-500 and 530-650 nm emission bandpass filters for CFP and citrine (YFP), respectively. GFP-PH fluorescence was excited at $488 \mathrm{~nm}$ laser line and emission was monitored at 505-550 nm.

Ratiometric calcium measurements were conducted on HeLa cells loaded with $5 \mu \mathrm{M}$ of Fura-2 AM in the presence of $0.05 \%$ Pluronic $\mathrm{F}-127$ for $30 \mathrm{~min}$ at room temperature. Leica AOBS SP2 microscope was used in these experiments. Laser lines, 351 and $405 \mathrm{~nm}$, were used to excite the indicator; emission was collected at $430-570 \mathrm{~nm}$. Ratio of Fura-2 fluorescence at 351 and $405 \mathrm{~nm}$ was determined. The maximal values of derivative of Fura- 2 ratio curve were used to calculate the rates of calcium influx. Differentiation was produced using Origin software. To allow comparison between different groups of measurements, the derivative was normalized by the maximal amplitude of ratio for each individual trace. Calcium measurements in HeLa cells loaded with Fura Red $(5 \mu \mathrm{M}$ of Fura Red AM for $30 \mathrm{~min}$ at room temperature) were conducted on Zeiss LSM 510. The probe was excited with $488 \mathrm{~nm}$; emission filter used was LP560. The maximal values of derivative of normalized Fura Red curves (calculated using Origin software) were used to calculate the rates of calcium influx.

\section{Bioluminescence measurements}

Bioluminescent imaging of ATP was carried out using adenoviral construct of cytosol-targeted firefly luciferase Ad-CMV-Luc purchased from Vector Biolabs (Philadelphia, PA 19104, USA). RAMA37 cells were infected by addition of purified virus at approximate viral concentration 
of $1-7 \times 10^{7} \mathrm{PFU} / \mathrm{ml}$ of media. After $16-20 \mathrm{~h}$ of infection, the medium was changed to the extracellular solution, supplemented with $0.2 \mathrm{mM}$ luciferin, and imaging was performed. Cells in 35-mm glass-bottomed Petri dishes were mounted on the stage of inverted Nikon-Diaphot microscope attached to a Photek HRPCS 325-18 intensified charged couple device (CCD) camera (Photek Ltd, East Sussex, UK). Objective Fluor $\times 20, N A=0.75$ was used for bioluminescence imaging. The imaging system was contained within a dark room. Single photon events were recorded at 1-s intervals. The bioluminescence was than integrated for $60 \mathrm{~s}$, data analysis was performed using Photek Software. The background was subtracted, and integrated photon count (PC) was normalized to the photon count from the cells/clusters before the addition of mitochondria inhibitors. Data were presented as mean value $\pm \mathrm{SE}$ of mean (for both bioluminescence and fluorescence measurements).

\section{Results}

ATP depletion induced translocation of STIM1 to the plasma membrane

Pancreatic and breast cancer cell lines (PANC1 and RAMA37) as well as HeLa cells were utilized in this study. To visualize STIM1 localization the $C$ terminus of STIM1 was tagged with EYFP. Cells were transfected with STIM1-EYFP. In our initial experiments, we observed, for other cell types a well-documented, translocation of STIM1-EYFP and formation of fluorescent sub-plasmalemmal puncta using an inhibitor of the sarcoplasmic/endoplasmic reticulum calcium ATPase thapsigargin $(\mathrm{Tg} ; 5 \mu \mathrm{M})$ or a membrane-permeable low affinity calcium buffer $N, N, N^{\prime}, N^{\prime}$ Tetrakis(2-pyridylmethyl)ethylenediamine (TPEN) $1 \mathrm{mM}$ (not shown).

The next stage of the project involved depletion of cytosolic ATP. This was achieved by simultaneous inhibition of mitochondrial ATP production with an inhibitor of ATP synthase Oligomycin (Olig) and inhibition of glycolysis by iodoacetate (IA) or 2-deoxyglucose (2DOG). Combined application of Olig $(5 \mu \mathrm{M})$ and 2DOG $(10 \mathrm{mM})$ triggered formation of STIM1-EYFP puncta in RAMA37, PANC1, and HeLa cells (Fig. 1a $a-\mathrm{a} c, n=32$ for RAMA37; Fig. $1 \mathrm{c} a-\mathrm{c} c, n=3$ for PANC1 and Fig. $1 \mathrm{e} a-\mathrm{e} c, n=14$ for HeLa). A similar phenomenon was observed in these cell types after treatment with $5 \mu \mathrm{M}$ Olig and $2 \mathrm{mM}$ IA (see Fig. $1 \mathrm{~b} a-\mathrm{b} c, n=18$ for RAMA37; Fig. $1 \mathrm{~d} a-\mathrm{d} c n=3$ for PANC1 and Fig. $1 \mathrm{f} a-\mathrm{f} c, n=10$ for HeLa). The formation of STIM1 puncta was also triggered by Rotenone (Rot), the inhibitor of Complex I of the mitochondrial electron transport chain (not shown, $n=5$ for RAMA37). A substantial delay between application of inhibitors and formation of puncta was observed. The average time for formation of the first resolvable puncta was $773 \pm$ $586 \mathrm{~s}$ for Olig/2DOG and $623 \pm 333 \mathrm{~s}$ for Olig/IA (measured for RAMA37 cells).

Importantly, the process of STIM1 accumulation in puncta (with an increase of puncta fluorescence and decrease of fluorescence in regions outside the puncta) continued for a further $200-400 \mathrm{~s}$ after puncta formation. These results were surprising because we had anticipated that STIM1 translocation would be an active process and that it would therefore be efficiently inhibited by ATP depletion.

One of the potential consequences of ATP depletion is the depletion of phospholipids which are considered important for the targeting of STIM1 to the sub-plasmalemmal region [19]. We decided to test this using RAMA37 cells transfected with a GFP-labeled PH domain of $\operatorname{PLC}_{\delta 1}$. We observed that Olig/IA treatment results in the slow depletion of plasma membrane-bound GFP-PH. This translocation of GFP-PH from the vicinity of the plasma membrane to the cytosol was interpreted as the depletion of $\mathrm{PI}(4,5) \mathrm{P}_{2}$ [14]. By the time of the first STIM1 puncta formation (approximately $600 \mathrm{~s}$ ) the preferential subplasmalemmal GFP-PH localization was lost in the majority of cells (10 out of 14, Fig. 2a). Average time of the loss of preferential GFP-PH localization was $510 \pm 87$ s. It is clear that the Olig/IA-induced formation of the STIM1 puncta proceeds under conditions of reduced $\mathrm{PI}(4,5) \mathrm{P}_{2}$.

We also conducted experiments with high concentrations of wortmannin, which were reported to inhibit storeoperated $\mathrm{Ca}^{2+}$ influx [6] and deplete PI(4)P [6, 24]. In our experiments, high concentrations of wortmannin $(20 \mu \mathrm{M})$ did not produce a redistribution of GFP-PH $(n=8$, Fig. 2 b) and did not prevent formation of STIM1 puncta under conditions of Tg-induced store depletion ( $n=24$, Fig. 2c). Finally wortmannin did not inhibit STIM1 puncta formation induced by ATP depletion ( $n=17$, Fig. $2 \mathrm{~d}$ ). In these experiments, sub-plasmalemmal STIM1 puncta were present even after very prolonged treatment with wortmannin and Olig/IA (Fig. 2d).

To evaluate the time course and extent of the ATP depletion induced by the combined inhibition of oxidative phosphorylation and glycolysis, we transfected the cell lines with luciferase and measured ATP using bioluminescence. Treatment with the inhibitors induced a rapid decline of bioluminescence. Within 300-400 s after application of Olig and 2DOG (or Olig and IA), the bioluminescence recorded from RAMA37 cells became indistinguishable from the background (Fig. 3a, $n=7$ and $n=14$ for Olig/ 2DOG and Olig/IA treatment, respectively). These experiments taken together with the experiments shown in Fig. 1 indicate that formation of puncta starts and progresses under conditions of severe ATP depletion. 
Fig. 1 STIM1 translocation is induced by ATP depletion in RAMA37 and PANC1 cells. RAMA37 and PANC1 cells were transfected with STIM1-EYFP and imaged using confocal microscopy. Images of the cells just before application of inhibitors of ATP production $(t=0)$ are shown in the left column. Scale bars correspond to $5 \mu \mathrm{m}$. Depleting ATP with Oligomyin and 2-Deoxy-D-glucose (Olig/ 2DOG), or with Oligomyin and Iodoacetate (Olig/IA) causes STIM1-EYFP to translocate into discrete puncta in both RAMA37 (a-b), PANC1 (c-d), and HeLa (e-f) cells. Time for which cells were exposed to the inhibitors is indicated on individual images
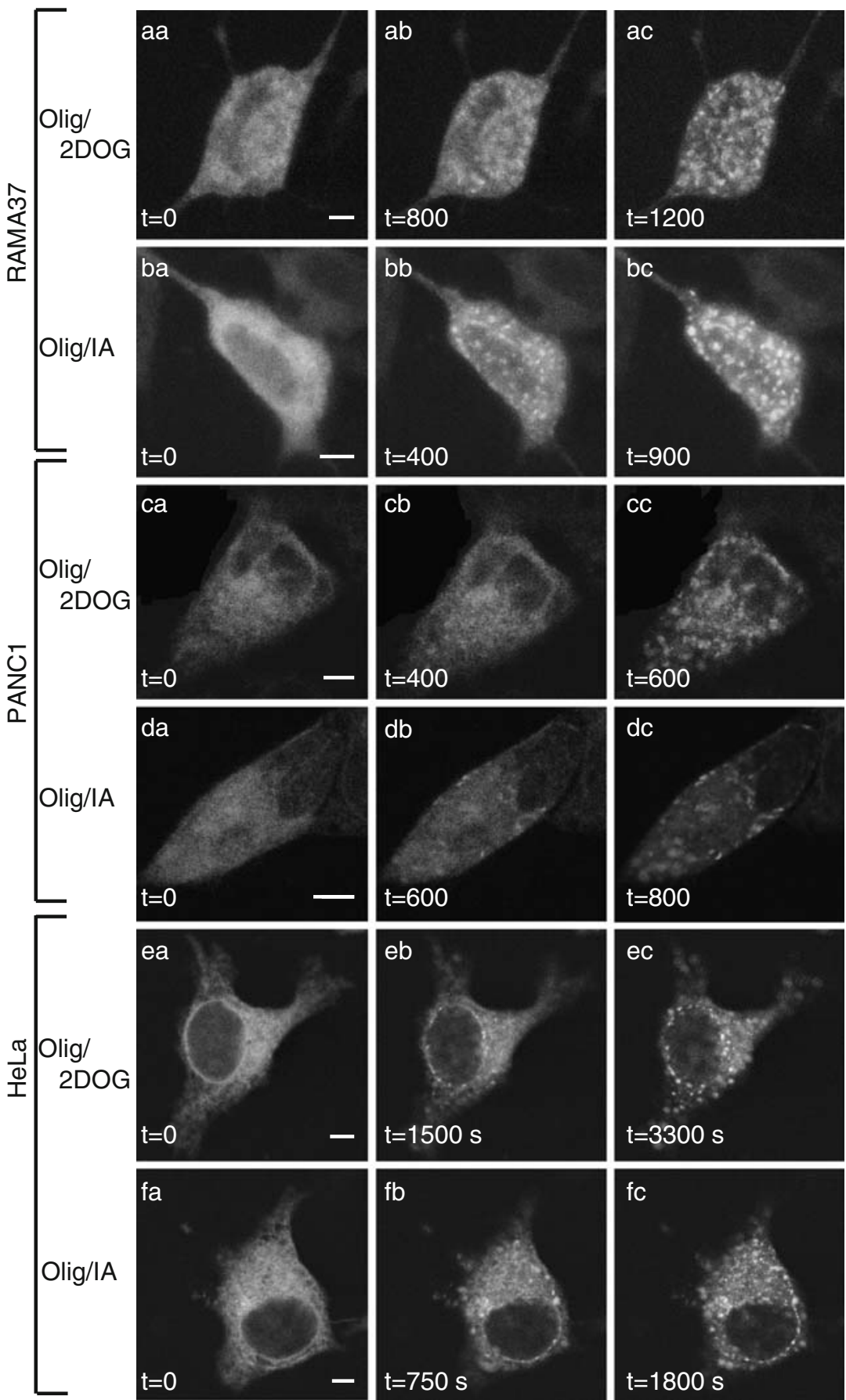

Translocation of STIM1 induced by ATP depletion is triggered by depleting the ER of $\mathrm{Ca}^{2+}$

At the next stage of the project, it was important to investigate if ATP depletion per se or the consequent depletion of $\mathrm{Ca}^{2+}$ in the ER induces the observed STIM1 translocation. These experiments were conducted on RAMA37 cells. To measure $\left[\mathrm{Ca}^{2+}\right]$ in the ER $\left(\left[\mathrm{Ca}^{2+}\right]_{\mathrm{ER}}\right)$ under conditions of ATP depletion, we transfected the cells with an ER-targeted low affinity calcium sensor cameleon D1ER (gift from Roger Y. Tsien, University of California at San Diego). Application of inhibitors of ATP production to RAMA37 cells triggered a very slow decline in $\left[\mathrm{Ca}^{2+}\right]_{\mathrm{ER}}$ (Fig. 3b). Most probably, the net loss of ER calcium in these conditions develops as a result of the inability of SERCA to transport $\mathrm{Ca}^{2+}$ into the ER. This unmasks the calcium leak which decreases $\left[\mathrm{Ca}^{2+}\right]_{\mathrm{ER}}$.

Comparison of the time required for the first puncta formation with measurements of ER calcium loss triggered by Olig/IA and Olig/2DOG (see Fig. 3b) revealed that only 

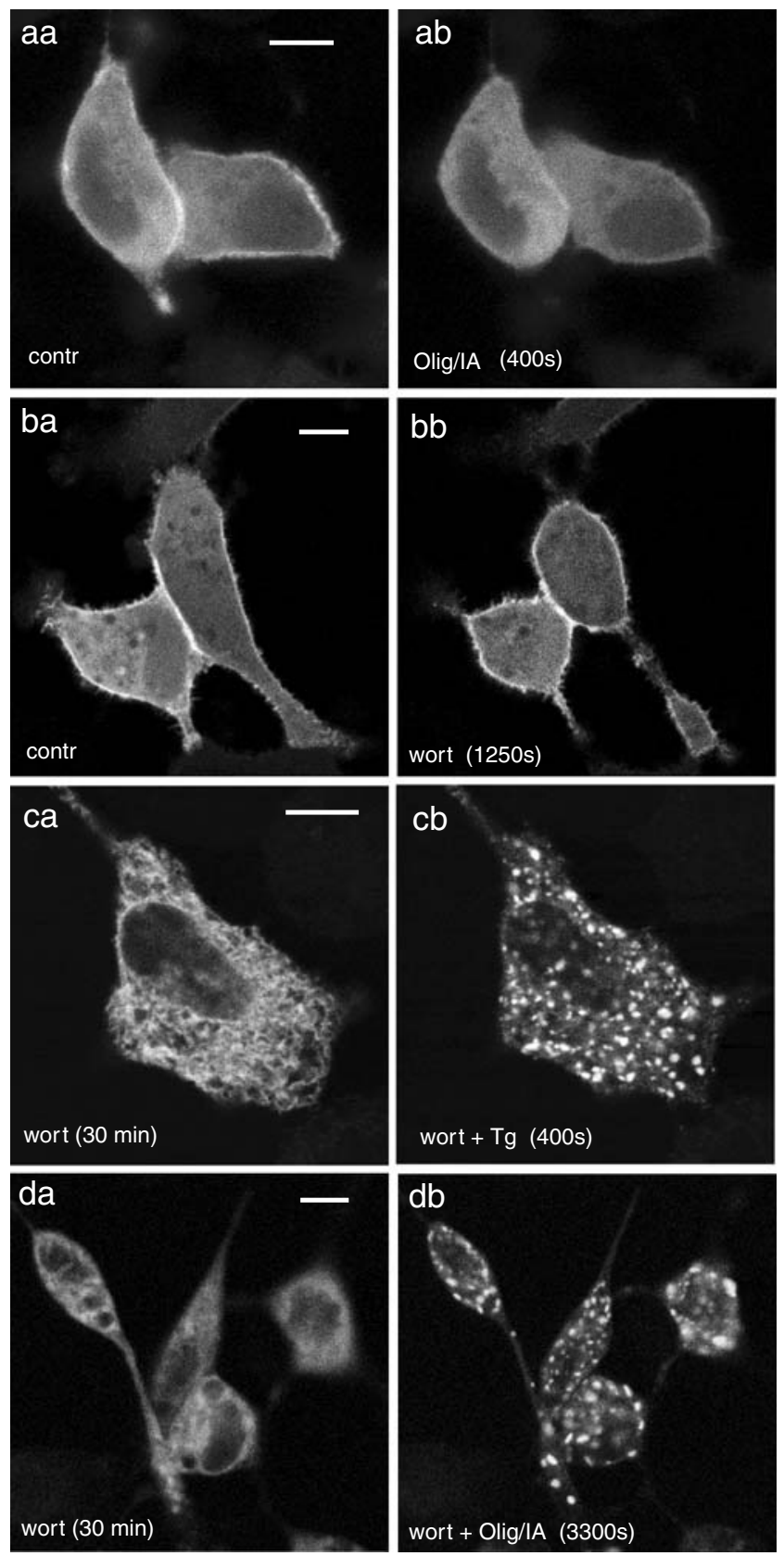

Fig. 2 Effects of ATP depletion and wortmannin on $\mathrm{PI}(3,4) \mathrm{P}_{2}$ content and STIM1 translocation. a, b Images of RAMA37 cells transfected with GFP-PH. Depleting ATP (a) with oligomyin and iodoacetate (Olig/IA) but not inhibition of PI3-kinase (b) by wortmannin $(20 \mu \mathrm{M})$ induces GFP-PH redistribution from plasma membrane to the cytosol. c, d Images of RAMA37 cells transfected with STIM1-EYFP. Incubation of cell in wortmannin (starting $30 \mathrm{~min}$ before the registration and continuing through the experiment) does not prevent STIM1 translocation caused by thapsigargin (Tg) or oligomyin plus iodoacetate (Olig/IA). Time for which cells were exposed to the inhibitors is indicated on individual images. Scale bars correspond to $8 \mu \mathrm{m}$

a small decline of $\left[\mathrm{Ca}^{2+}\right]_{\mathrm{ER}}$ can be detected by the time of the first puncta formation (corresponding to a decrease of fluorescence ratio by only $6-8 \%$ ). To probe if this modest reduction of $\left[\mathrm{Ca}^{2+}\right]_{\mathrm{ER}}$ is sufficient to trigger STIM1 translocation, independently of ATP depletion, we produced graded decreases in $\left[\mathrm{Ca}^{2+}\right]_{\mathrm{ER}}$ using different concentrations of TPEN, utilizing a procedure similar to that described by Hofer and colleagues [15], and studied the effects of these graded decreases on puncta formation. We observed that TPEN at the concentrations tested $(0.1,0.3$, and $1 \mathrm{mM}$ ) produced rapidly achievable steady state levels of decreased $\left[\mathrm{Ca}^{2+}\right]_{\mathrm{ER}}$ (see Fig. 4a). The decrease of the ratio of D1ER fluorescence induced by $0.3 \mathrm{mM}$ TPEN (approximately 5\%) was similar to the decline observed due to inhibition of ATP production at the moment the first puncta were formed. In separate experiments, we tested the ability of TPEN $(0.1-1.0 \mathrm{mM})$ to trigger puncta formation (Fig. $4 \mathrm{~b}$ and c). After treatment with $0.1 \mathrm{mM}$ TPEN (see Fig. $4 \mathrm{~b}$ and $\mathrm{c} b$ ), puncta were observed in a substantial proportion of the cells (four out of ten cells later showing responses to $1 \mathrm{mM}$ TPEN). This proportion increased to $100 \%$ for $0.3 \mathrm{mM}$ of TPEN (all ten cells that eventually responded to $1 \mathrm{mM}$ TPEN responded to $0.3 \mathrm{mM}$ as well, see Fig. $4 c c$ ). The density and brightness of puncta increased with further increases of the TPEN concentration (Fig. $4 \mathrm{c} d, \mathrm{ce}$ ). The effect of TPEN was reversible-removal of TPEN resulted in recovery of $\left[\mathrm{Ca}^{2+}\right]_{\mathrm{ER}}$ (Fig. 4a) and restoration of diffuse STIM1-YFP fluorescence (Fig. 4cf).

Importantly, the magnitude of the $\left[\mathrm{Ca}^{2+}\right]_{\mathrm{ER}}$ decrease that resulted in puncta formation after ATP depletion also triggered puncta formation in experiments with TPEN titration (Fig. 4). This suggests that puncta formation induced by ATP depletion is explainable by the loss of $\left[\mathrm{Ca}^{2+}\right]$ in the ER calcium store.

\section{Re-translocation of STIM1 from puncta to bulk ER} is an ATP-independent process

We felt that it would be important also to investigate the ATP dependency of the re-translocation of STIM1-the process that restores the more uniform ER distribution of STIM1. Reversal of the punctuate distribution of STIM1 could be achieved after repletion of the ER calcium store. However, in the presence of Olig/2DOG or Olig/IA, we could not rely on SERCA pumps to reload $\mathrm{Ca}^{2+}$ into the $\mathrm{ER}$, as the pumps were incapacitated by lack of ATP.

Re-translocation of STIM1 from puncta was attained using the calcium ionophore ionomycin $(10 \mu \mathrm{M})$ with a moderate calcium concentration $\left(0.3-0.8 \mathrm{mM}\right.$ of $\left.\mathrm{Ca}^{2+}\right)$ in the extracellular solution. We initially tested this approach on cells that had lost $\mathrm{Ca}^{2+}$ from the ER as a result of Tg treatment. In these experiments, Tg application triggered translocation of STIM1 to puncta (Fig. 5a), while ionomycin in combination with $0.5 \mathrm{mM}$ extracellular $\mathrm{Ca}^{2+}$ induced re-translocation of STIM1 from a punctate to a more uniform distribution $(n=3)$. Similar phenomena were observed when ionomycin was applied in the presence of extracellular calcium after Olig/2DOG or 
Fig. 3 ATP depletion and decrease in $\left[\mathrm{Ca}^{2+}\right]_{\mathrm{ER}}$ induced by oligomycin with iodoacetate or oligomyin with 2-deoxyD-glucose. Traces represent average \pm SE for individual time points. a Luminescence measurements (photon counts normalized to initial control value) in populations of RAMA37 cells expressing cytosolictargeted luciferase. Changes of bioluminescence induced by oligomycin and iodoacetate $(n=14)$ are shown on $(\mathbf{a} a)$. Results of application of oligomycin and 2-deoxyglucose $(n=7)$ are shown on $(\mathbf{a} b)$. b Ratio of fluorescence of citrine (YFP) and CFP for RAMA-37 cells expressing ER-targeted cameleon D1ER. $\mathbf{b} a$ Results of application of oligomycin and iodoacetate $(n=31)$. b $b$ shows fluorescence ratio changes due to application of oligomycin and

2-deoxyglucose $(n=27)$ aa

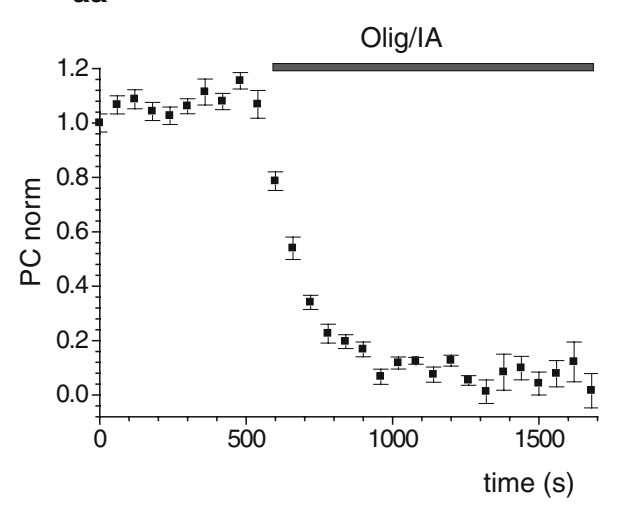

ba

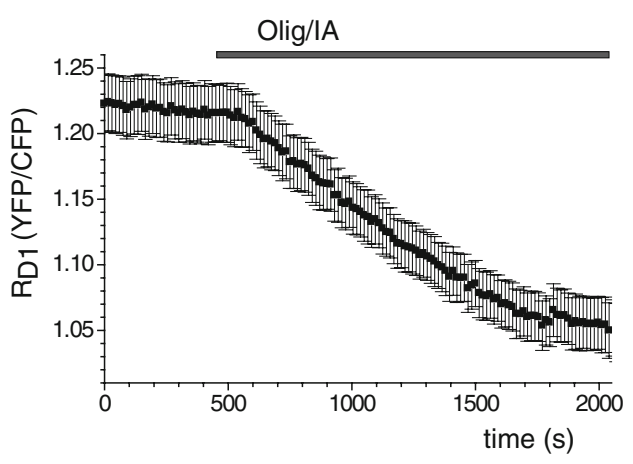

ab

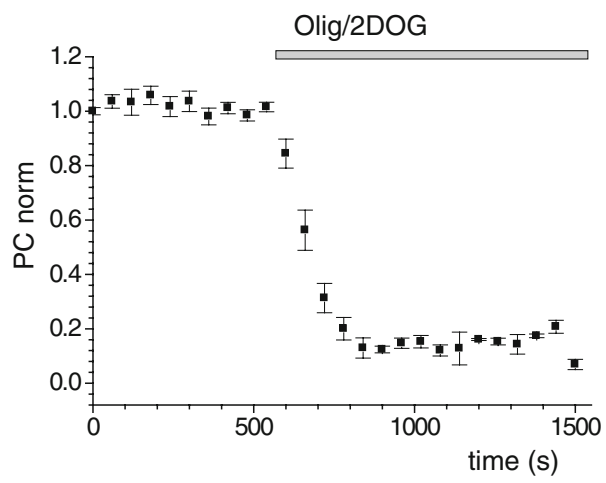

bb

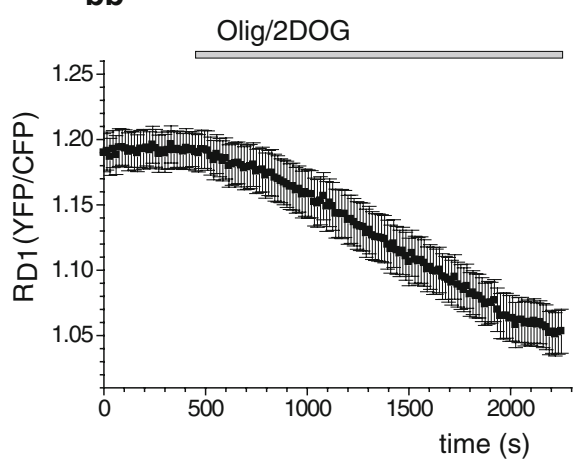

Olig/IA incubation (Fig. 5b and c correspondingly; $n=6$ for Olig/2DOG and $n=13$ for Olig/IA). In all such experiments, we were able to attain substantial re-translocation (i.e., substantial decrease of puncta brightness and more uniform distribution of fluorescence). We were, however, limited by the time available for inducing and observing re-translocation because soon (100-400 s) after the addition of ionomycin in calcium-containing extracellular solution, the cells started to bleb. Due to this limitation, in some experiments, we observed only partial re-translocation (e.g., Fig. 5b). Changes of D1ER fluorescence ratio (Fig. 5d) reflect the loss of $\mathrm{ER} \mathrm{Ca}^{2+}$ as a result of ATP depletion and further decrease of $\left[\mathrm{Ca}^{2+}\right]_{\mathrm{ER}}$ by treatment with ionomycin and calcium-free extracellular solution and increase/restoration of ER calcium content after application of ionomycin and moderate extracellular $\left[\mathrm{Ca}^{2+}\right]$. In these experiments (Fig. 5b,c), re-translocation of STIM1 from a punctate to a more uniform distribution was attained in cells that were treated by inhibitors of ATP production for more than $30 \mathrm{~min}$. This strongly suggests that re-translocation of STIM1 can occur in an ATPindependent manner, and therefore, it does not require active molecular motoring.

ATP depletion induces formation of co-localized puncta of STIM1 and ORAI1

In cells co-expressing STIM1-EYFP and ORAI1-mCherry, we observed that depletion of ATP using Olig/IA (Fig. 6, $n=$
7) or Olig/2DOG (not shown, $n=2$ ) resulted in formation of STIM1 puncta which were co-localized with puncta of ORAI1. We found that out of the cell lines used in our experiments, HeLa cells were the most convenient model for such dual expression experiments. Little or no co-localization of the two constructs was observed before the inhibition of ATP production (Fig. $6 \mathrm{a} a-\mathrm{a} c$ ). ATP depletion resulted in formation of puncta of STIM1 accompanied with clustering of ORAI1 in the same puncta (Fig. $6 \mathrm{~b} a-\mathrm{b} c$ and $\mathrm{c} a-\mathrm{c} c$ ).

ATP depletion inhibits $\mathrm{Ca}^{2+}$ influx induced by thapsigargin and produces very slow influx on its own in spite of prominent puncta formation

Thapsigargin treatment induced efficient store-operated $\mathrm{Ca}^{2+}$ entry in HeLa cells, revealed as changes of Fura-2 ratio due to addition of calcium-containing solution. The rate of the entry was three times higher in cells transfected with STIM1 and ORAI1. In Fig. $7(\mathrm{a} a-\mathrm{b} c)$, we show the normalized rate of entry (normalized by dividing individual traces by maximal average peak of ratio of Fura2 fluorescence). This allows a comparison of the responses between transfected and non-transfected cells and between different groups of measurements. The rate of calcium entry is almost unchanged between the first and the second application of calcium-containing ( $2 \mathrm{mM}$ of $\mathrm{Ca}$ ) extracellular solution for both transfected (Fig. 7a $a$ and $\mathrm{ac}$ ) and untransfected (Fig. 7ba and bc) cells. There is however a 
Fig. 4 Dose-response for TPEN-induced $\left[\mathrm{Ca}^{2+}\right]_{\text {ER }}$ depletion and STIM1-EYFP translocation. a Ratio of fluorescence of citrine (YFP) and CFP for RAMA-37 cells expressing ERtargeted cameleon D1ER $(n=19)$. b Representative experiment, in which cell displayed STIM1EYFP translocation in the presence of $0.1 \mathrm{mM}$ TPEN c Representative experiment, in which the cell on the right (marked with arrowhead) showed STIM1-EYFP translocation in the presence of $0.1 \mathrm{mM}$ TPEN and the remaining three cells only responded to $0.3 \mathrm{mM}$ TPEN. In all experiments TPEN was applied in zero-calcium extracellular solution supplemented with $0.2 \mathrm{mM}$ EGTA. Scale bars in $\mathbf{b}$ and $\mathbf{c}$ correspond to $8 \mu \mathrm{m}$
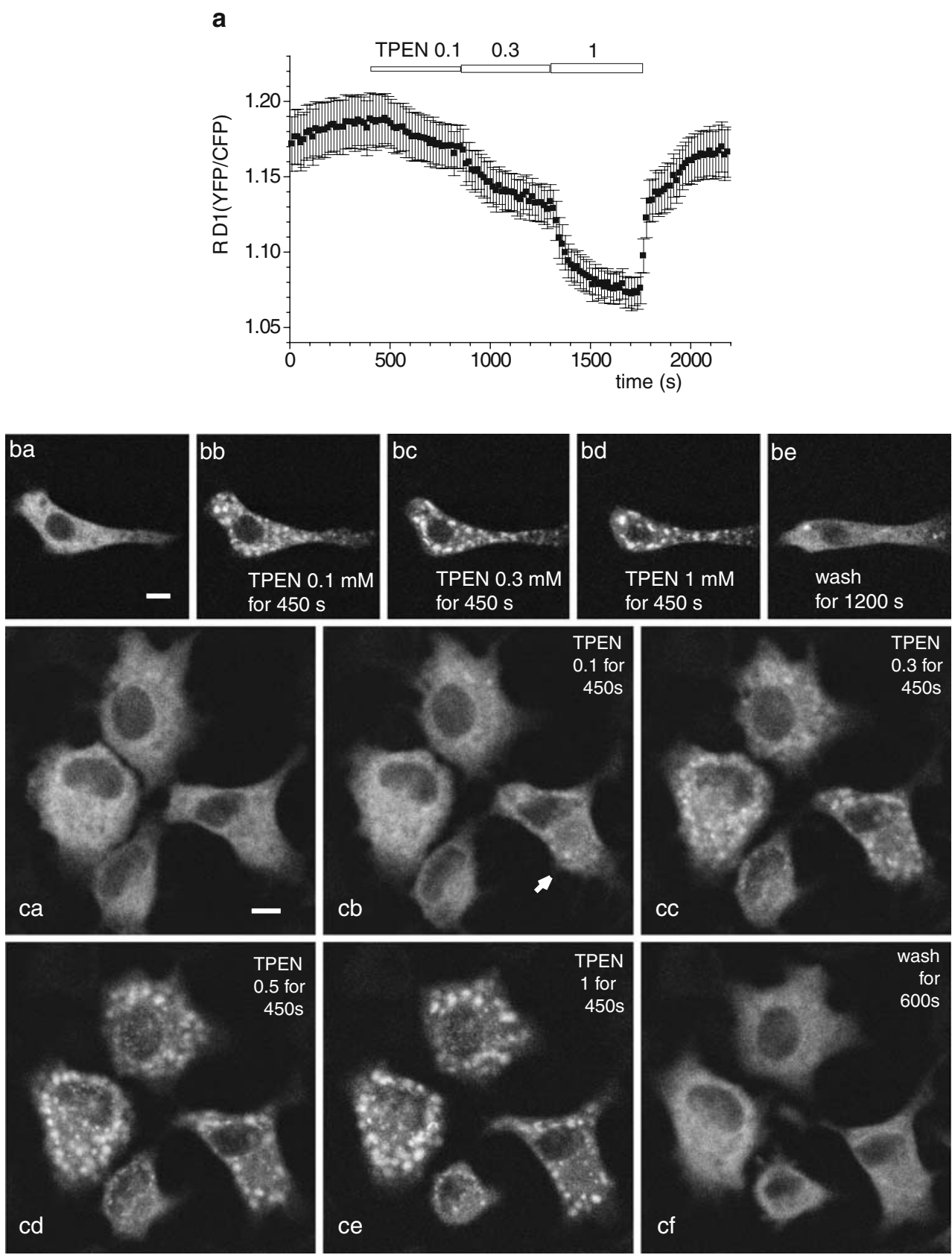

drastic inhibition of $\mathrm{Ca}^{2+}$ influx by Olig/IA treatment (compare the first and the second application of calciumcontaining solution) for both transfected (Fig. 7a $b$ and $\mathrm{a} c$ ) and untransfected (Fig. $7 \mathrm{~b} b$ and $\mathrm{b} c$ ) cells. We also evaluated $\mathrm{Ca}^{2+}$ influx induced by Olig/IA treatment per se. The influx induced by Olig/IA was impossible to resolve in untransfected cells $(\mathrm{n}=15$, not shown). In cells transfected by STIM1 and Orai1, we were able to resolve $\mathrm{Ca}^{2+}$ influx induced by Olig/IA (see Fig. 7ca and $\mathrm{c} b$ ). The rate of influx was approximately 12 times slower than for the influx induced by the depletion of calcium stores with thapsigargin (see Fig. 7cb). At the beginning of the experiments, we verified that cells were transfected with STIM1 and ORAI1, and at the end of experiments, we verified that the puncta were formed. During experiments shown on Fig. 7c, we monitored Fura Red fluorescence (which decreases with the increase of $\left[\mathrm{Ca}^{2+}\right]$ ). These results (Fig. 7) indicate that ATP depletion induces formation of STIM1/ORAI1 complexes which are very poor mediators of calcium influx (and even if complexes are formed by conventional store depletion with thapsigargin, subsequent ATP depletion strongly inhibits the $\mathrm{Ca}^{2+}$ influx). 
Fig. 5 STIM1-EYFP translocation induced by ER calcium depletion can be reversed by ionomycin and moderate extracellular calcium. a The reversal of thapsigargin-induced STIM1YFP translocation. b STIM1 translocation to puncta induced by ATP depletion with Oligomycin and Iodoacetate is partially reversed by ionomycin and $0.5 \mathrm{mM}$ external calcium. c STIM1 translocation to puncta induced by ATP depletion with Oligomycin and 2-deoxyD-glucose is partially reversed by ionomycin and $0.8 \mathrm{mM}$ external calcium. Scale bars in (a), (b), and (c) correspond to $8 \mu \mathrm{m}$. d A representative cell transfected with $\left[\mathrm{Ca}^{2+}\right]_{\mathrm{ER}}$-sensitive chameleon D1ER showing changes of citrine (YFP)/CFP ratio in response to oligomycin $5 \mu \mathrm{M}$ plus 2-deoxyglucose $10 \mathrm{mM}$ and then to ionomycin plus low and high calcium
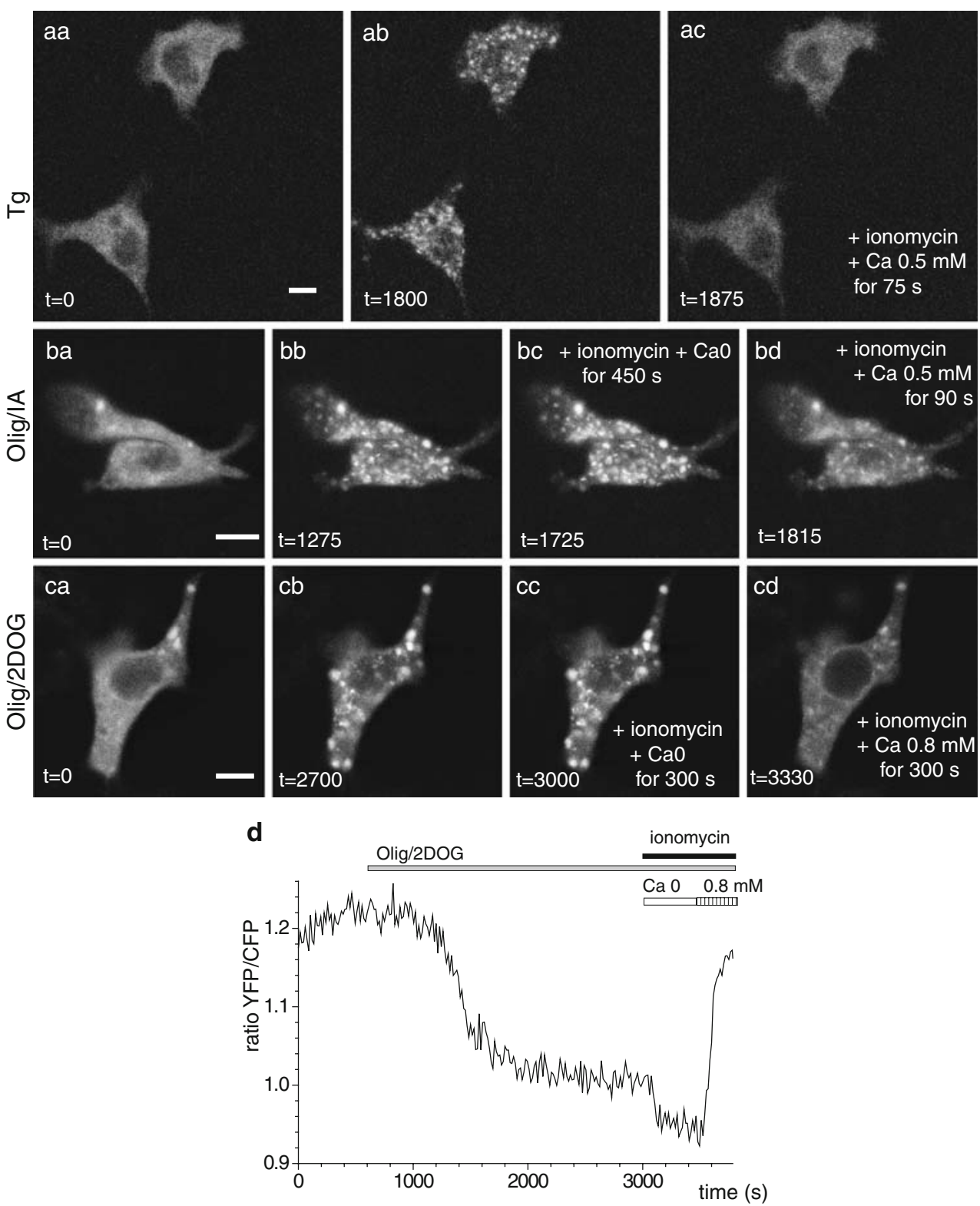

\section{Discussion}

The results of this study indicate that the complete cycle of STIM1 translocation, namely, formation of puncta in the vicinity of the plasma membrane and re-translocation from puncta to the bulk ER can occur in ATP-depleted cells. This finding could have important consequences for hypoxiareperfusion injury in a variety of tissues. After a period of hypoxia, STIM1 will be assembled into sub-plasmalemmal puncta. Even more strikingly, ATP depletion induced the formation of STIM1-ORAI1 complexes. In other words, the complete machinery for calcium influx is assembled due to energy depletion (Fig. 6). A number of studies, however, indicated that inhibition of mitochondria and/or more generally of ATP production suppressed store- operated $\mathrm{Ca}^{2+}$ influx $[3,9,11,16,23]$. Our results certainly support this notion. ATP depletion produced STIM1ORAI1 complexes and resolvable calcium influx (at least in cells transfected with both STIM1 and ORAI1), but this influx was much slower than in cells with calcium stores depleted by thapsigargin. The fact that we failed to resolve $\mathrm{Ca}^{2+}$ influx in untransfected cells upon ATP depletion is perhaps not surprising, as this process is expected to be much slower than thapsigargin-induced influx, and in this particular case, it is not amplified by STIM1/ORAI1 coexpression. As in previous studies [3, 9, 23], our work indicates that ATP depletion inhibits thapsigargin-induced store-operated calcium entry. In the case of HeLa cells, inhibition was very efficient and observed in both untransfected cells and cells co-transfected with STIM1 and 
Fig. 6 ATP depletion induced changes in STIM1-EYFP and mCherry-Orai1 cellular localizations. a The upper panel shows gray-scale images of STIM1-EYFP (a $a$ ) and mCherry-Orail (a $b$ ) fluorescence as well as their colorcoded (green for STIM1-EYFP and red for mCherry-Orail) overlay $(\mathbf{a} c)$. Scale bar corresponds to $12 \mu \mathrm{M}$. b The panel shows the corresponding images (STIM1-EYFP distribution on $\mathbf{b} a$, mCherry-Orail on $\mathbf{b} b$, and overlay on $\mathbf{b} c$ ) after oligomycin and iodoacetate treatment for 15 min. c The enlarged images of STIM1-EYFP (ca), mCherryOrail $(\mathbf{c} b)$, and their overlay (cc) of the area outlined as white $b o x$ in $\mathbf{b} c$. $\mathbf{d}$ The profile of pixel fluorescence intensity along the white line shown on $c c$. Top trace (green) for STIM1-EYFP and red trace (bottom) for mCherry-Orai1
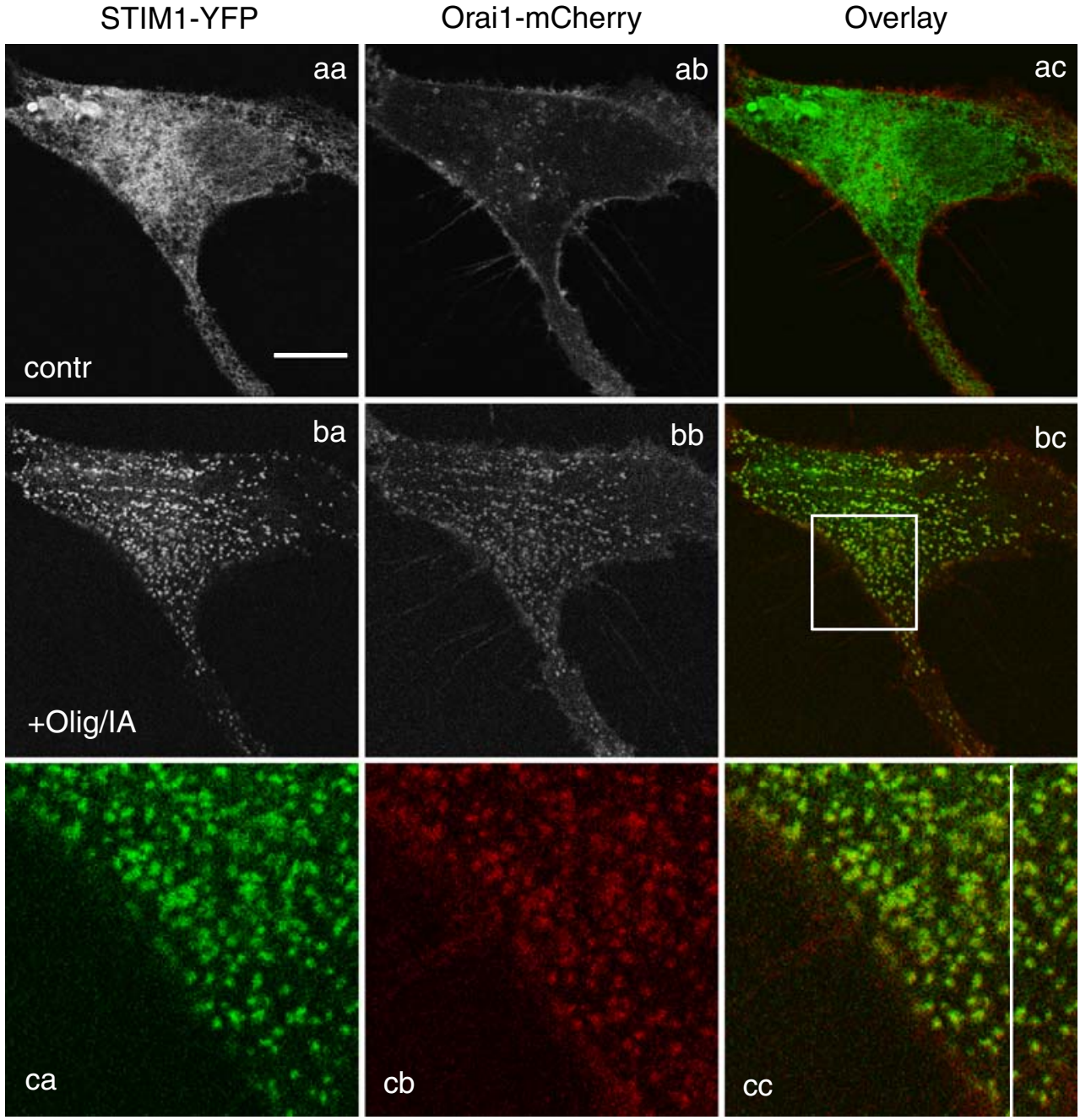

d

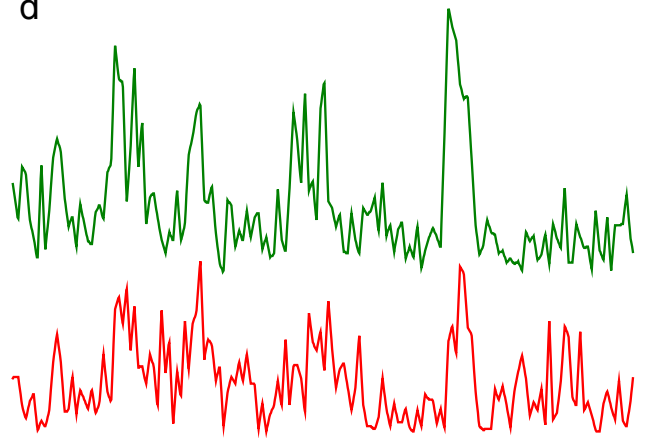

ORAI1. It seems therefore that cells have developed mechanisms preventing or delaying $\mathrm{Ca}^{2+}$ influx (and consequent calcium toxicity), and these mechanisms operate in spite of the successful assembly of STIM1-ORAI1 complexes in ATP-depleted cells. These preventative mechanisms will be investigated in further studies.

The characteristics of the ER-plasma membrane junctions necessary for STIM1 translocation to sub-plasmalemmal regions were recently discussed by Varnai and colleagues [43]. In their study, chemically induced linkers were used to form PM-ER complexes. After ER $\mathrm{Ca}^{2+}$ depletion, STIM1 complexes were found on the periphery of junctional ER clusters. This suggests that a proportion of the structures guiding STIM1 to its sub-plasmalemmal docking stations are already preassembled. Preassembled ER-plasma membrane junctions were also described in a study by $\mathrm{Wu}$ and colleagues [46]. Our study indicates that active transport of ER components towards the plasma 
Fig. 7 ATP depletion inhibits $\mathrm{Ca}^{2+}$ influx. (a $a, \mathbf{a} b$ and $\left.\mathbf{b} a \mathbf{b} b\right)$. Ratio of Fura-2 fluorescence at 351 and $405 \mathrm{~nm}$ normalized by the average first peak value (produced as the result of the first addition of $\mathrm{Ca} 2 \mathrm{mM}$ containing solution after the store depletion with $\mathrm{Tg}$ ) in each population in either HeLa cells transfected with both STIM1EYFP and mCherry-Orail (a) or untransfected HeLa cells (b). Traces represent average \pm SE for individual time points $(n=10$, 14,14 , and 35 for $\mathbf{a} a, \mathbf{a} b, \mathbf{b} a$, and $\mathbf{b} b$, respectively). Note that the second additions of calcium containing solution (Ca $2 \mathrm{mM}$ ) in $(\mathbf{a} b)$ and $(\mathbf{b} b)$ were done in the presence of Olig/IA. (ac and bc) Average and SEM for maximal first derivative of Fura-2 ratio at 351 and $405 \mathrm{~nm}$ excitation during the first and the second additions of $2 \mathrm{mM} \mathrm{Ca}{ }^{2+}$ (from the traces generated by the protocols illustrated on part $\mathbf{a} a$, $\mathbf{a} b, \mathbf{b} a$, and $\mathbf{b} b$ ). The values of derivative were normalized for each cell by the average peak value of the ratio in the whole given population of cells. $\mathbf{c} a$ Normalized fluorescence of Fura Red (excited at $488 \mathrm{~nm}$ ) from two typical cells with $\mathrm{Ca}^{2+}$ stores depleted after $40 \mathrm{~min}$ incubation in Ca-free solution and either thapsigargin (black trace) or oligomycin plus iodoacetate (gray trace). $\mathbf{c} b$ The calculated maximal rates of decrease of Fura Red fluorescence (from the traces generated by the protocol illustrated on part $\mathbf{c} a$ ) shown as mean $\pm \operatorname{SEM}(n=9$ for Tg group and 11 for Olig/IA group)
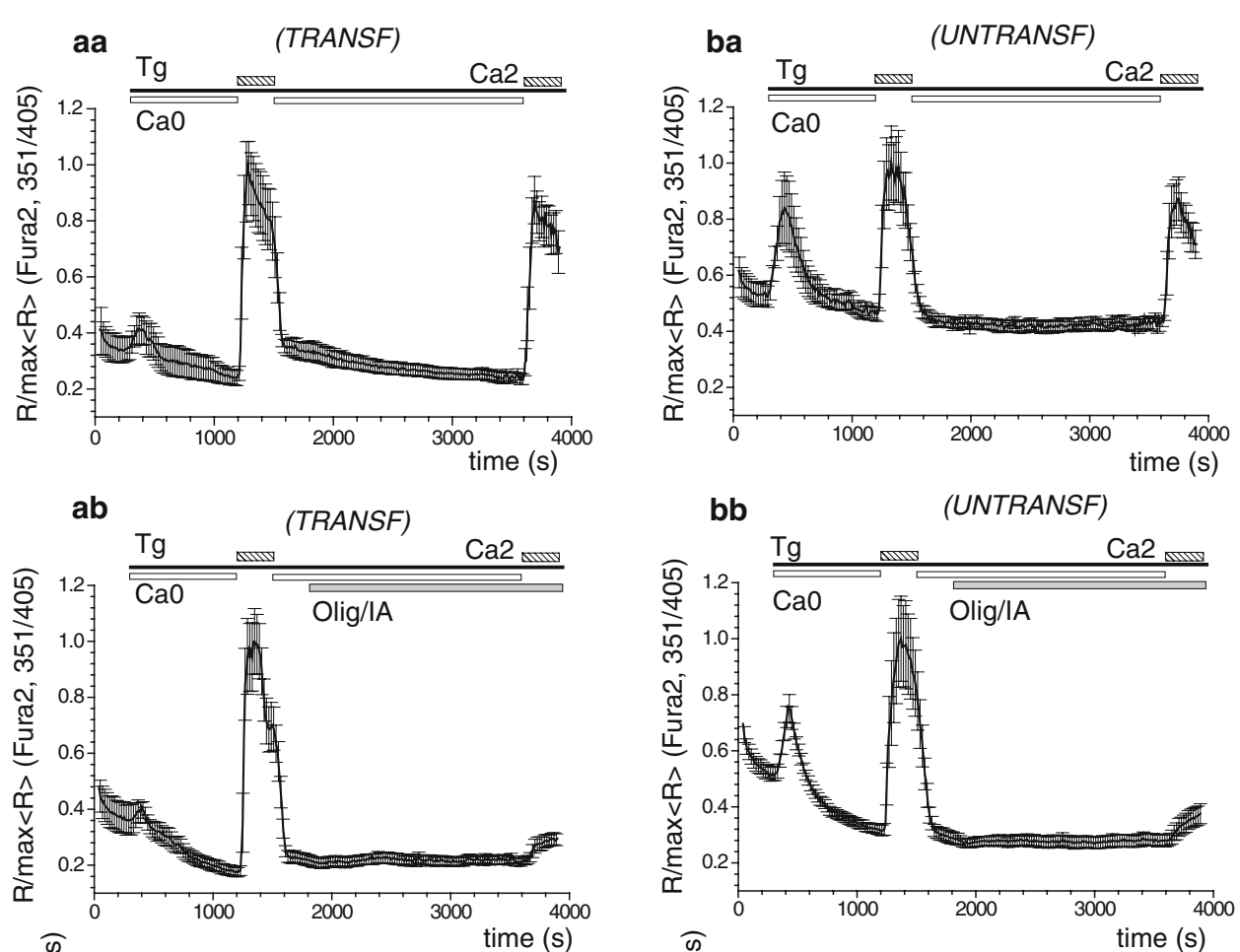

bb

(UNTRANSF)
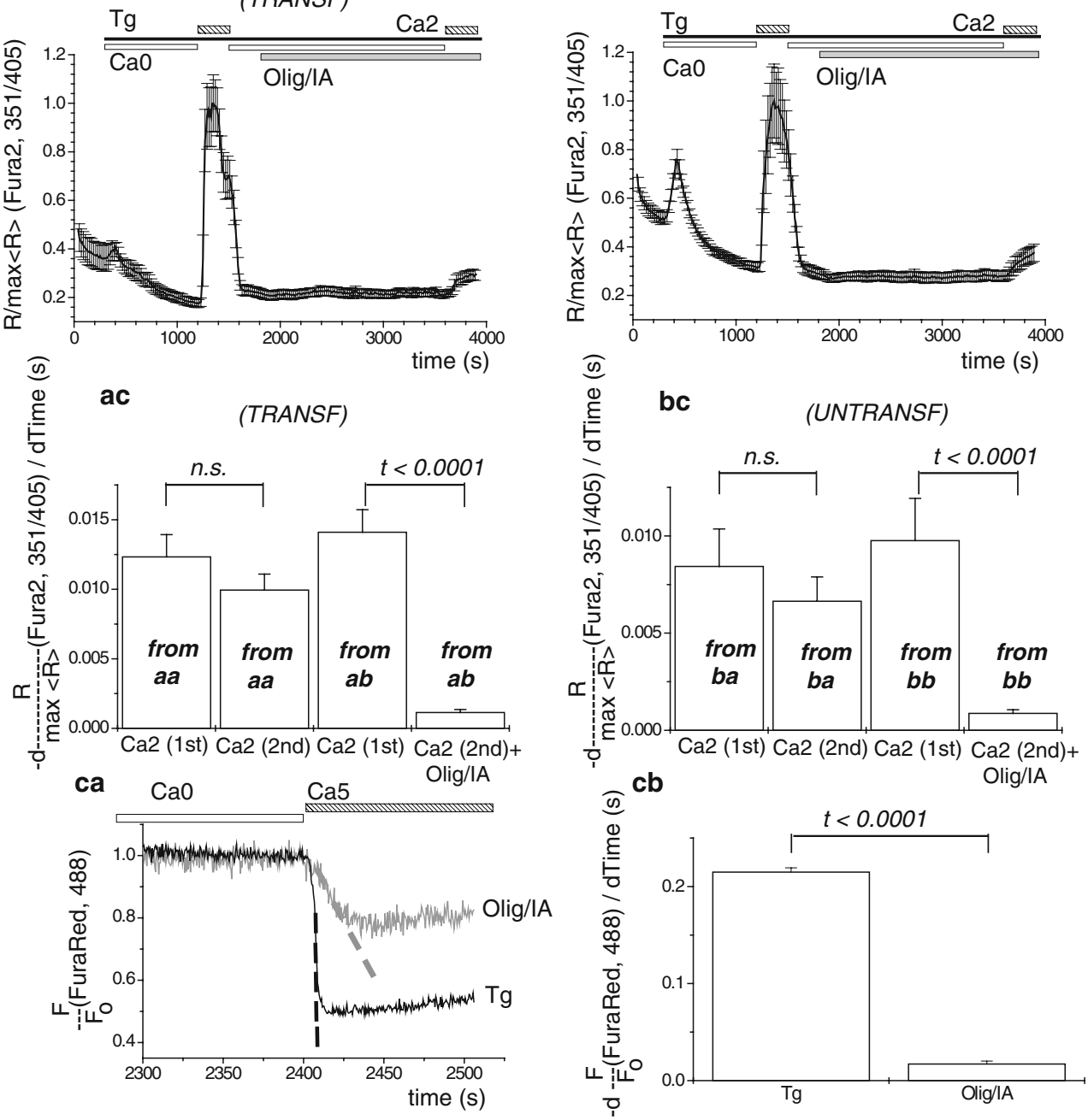

membrane is not an absolute prerequisite for STIM1 translocation. We cannot exclude, of course, that some additional ER structures could be actively transported under conditions of normal energy supply.

A topic which has been vigorously discussed in the field is whether STIM1 in puncta is sub-plasmalemmal or is actually inserted into the plasma membrane $[13,46]$. We have not addressed this question directly, but the ATPindependence of STIM1 translocation and re-translocation suggests that its movement is unlikely to be mediated by exocytic-endocytic processes.

An important question is the nature of the ATPindependent mechanism used for STIM1 translocation and the involvement of the cytoskeleton in this translocation. Recent publications characterized microtubule-dependent transport of STIM1-containing ER strands [12, 40]. This transport process is probably important for structuring the ER (and should depend on GTP levels and therefore on cell 
energetics), but it was shown to be unrelated to puncta formation [12, 40].

A possible explanation of the mechanism of the ATPindependent formation of STIM1 puncta comes from the study by Liou et al. [19]. They propose that the mechanism of translocation involves oligomerization of STIM1 (induced by the decrease of $\left[\mathrm{Ca}^{2+}\right]_{\mathrm{ER}}$ ) followed by its translocation to sub-plasmalemmal puncta [19]. The oligomerization unmasks a polybasic motif in the $\mathrm{C}$-terminal part of STIM1, which confers on the molecule the ability to bind to plasma membrane lipids. Binding of STIM1 to the plasma membrane depletes STIM1 in the junctional ER region and induces a preferential diffusion of STIM1 oligomers from the bulk ER towards the forming puncta [19]. This diffusion-based process does not necessitate direct ATP involvement. The process could be guided by the microtubular cytoskeleton [40]. However, considering the outcome of previous publications $[12,40]$ and of this study, it is unlikely that it involves ATP-requiring molecular motors. The fact that the process of protein translocation involves diffusion does not a priori mean that it is ATP independent - for example, the protein may need to be phosphorylated or appropriately folded by ATP-dependent enzymes to partake in translocation.

ATP is necessary for maintaining the plasma membrane pool of phospholipids, which are considered to be important for STIM1 puncta formation [19]. The changes in GFP$\mathrm{PH}$ distribution, induced by Olig/IA, indicate that $\mathrm{PI}(4,5) \mathrm{P}_{2}$ is usually depleted by the time of formation of the first STIM1 puncta. The rate of Olig/IA-induced $\mathrm{PI}(4,5) \mathrm{P}_{2}$ depletion is relatively slow, and it is not possible to make a definitive conclusion that $\mathrm{PI}(4,5) \mathrm{P}_{2}$ is not required for the STIM1 puncta formation. It is however clear that the STIM1 puncta can form in conditions of substantial depletion of $\mathrm{PI}(4,5) \mathrm{P}_{2}$. Our results are in agreement with the study of Varnai and colleagues which reported that the depletion of $\mathrm{PI}(4,5) \mathrm{P}_{2}$ has no effect on store-operated calcium influx [42].

High concentrations of wortmannin were shown to deplete $\mathrm{PI}(4) \mathrm{P}$ but not $\mathrm{PI}(4,5) \mathrm{P}_{2}[6,24]$. In our experiments, wortmannin did not prevent plasma membrane GFP-PH localization. Wortmannin also did not block formation of STIM1 puncta induced by Tg or Olig/IA treatment. The presence of STIM1 puncta in cells treated for a prolonged period of time by Olig/IA and high concentrations of wortmannin suggests that $\mathrm{PI}(4) \mathrm{P}$ and $\mathrm{PI}(4,5) \mathrm{P}_{2}$ are not essential for the long-term maintenance of the sub-plasmalemmal puncta.

More specific tools for fast and controlled depletion of individual phospholipids should be used in further studies to investigate the importance of these molecules for STIM1 puncta formation and retention.
Direct measurements of STIM1 translocation under conditions of ATP depletion, as shown in our study, reinforce diffusional models of puncta formation and specify that both translocation to puncta and re-translocation from puncta to the bulk of the ER are ATP-independent processes.

Acknowledgements We thank Mark Houghton and Josef Carroll for technical assistance. We are grateful to Alan Conant for useful discussions of the manuscript. The work was supported by an MRC programme grant to A.V.T., O.V.G., O.H.P., and by the Wellcome Trust Prize Ph.D. studentships to C. M. W. and G. L. and by a Wellcome Trust Project grant to R.D.B.

Open Access This article is distributed under the terms of the Creative Commons Attribution Noncommercial License which permits any noncommercial use, distribution, and reproduction in any medium, provided the original author(s) and source are credited.

\section{Reference}

1. Alonso MT, Villalobos C, Chamero P, Alvarez J, Garcia-Sancho J (2006) Calcium microdomains in mitochondria and nucleus. Cell Calcium 40:513-525

2. Bakowski D, Parekh AB (2007) Regulation of store-operated calcium channels by the intermediary metabolite pyruvic acid. Curr Biol 17:1076-1081

3. Barrow SL, Voronina SG, da SX, Chvanov MA, Longbottom RE, Gerasimenko OV, Petersen OH, Rutter GA, Tepikin AV (2008) ATP depletion inhibits $\mathrm{Ca}(2+)$ release, influx and extrusion in pancreatic acinar cells but not pathological $\mathrm{Ca}(2+)$ responses induced by bile. Pflugers Arch 455:1025-1039

4. Berridge MJ (1995) Capacitative calcium entry. Biochem J 312(Pt 1):1-11

5. Brandman O, Liou J, Park WS, Meyer T (2007) STIM2 is a feedback regulator that stabilizes basal cytosolic and endoplasmic reticulum $\mathrm{Ca}(2+)$ levels. Cell 131:1327-1339

6. Broad LM, Braun FJ, Lievremont JP, Bird GS, Kurosaki T, Putney JW Jr. (2001) Role of the phospholipase C-inositol 1,4,5trisphosphate pathway in calcium release-activated calcium current and capacitative calcium entry. J Biol Chem 276:1594515952

7. Burgoyne RD, Morgan A (2003) Secretory granule exocytosis. Physiol Rev 83:581-632

8. Feske S, Gwack Y, Prakriya M, Srikanth S, Puppel SH, Tanasa B, Hogan PG, Lewis RS, Daly M, Rao A (2006) A mutation in Orai1 causes immune deficiency by abrogating CRAC channel function. Nature 441:179-185

9. Gamberucci A, Innocenti B, Fulceri R, Banhegyi G, Giunti R, Pozzan T, Benedetti A (1994) Modulation of $\mathrm{Ca}^{2+}$ influx dependent on store depletion by intracellular adenine-guanine nucleotide levels. J Biol Chem 269:23597-23602

10. Gilon P, Obie JF, Bian X, Bird GS, Putney JW Jr (1995) Role of cyclic GMP in the control of capacitative $\mathrm{Ca}^{2+}$ entry in rat pancreatic acinar cells. Biochem J 311(Pt 2):649-656

11. Glitsch MD, Bakowski D, Parekh AB (2002) Store-operated $\mathrm{Ca}^{2+}$ entry depends on mitochondrial $\mathrm{Ca}^{2+}$ uptake. EMBO J 21:6744 6754 
12. Grigoriev I, Gouveia SM, van d V, Demmers J, Smyth JT, Honnappa S, Splinter D, Steinmetz MO, Putney JW Jr, Hoogenraad CC, Akhmanova A (2008) STIM1 Is a MT-Plus-End-Tracking protein involved in remodeling of the ER. Curr Biol 18:177182

13. Hauser CT, Tsien RY (2007) A hexahistidine- $\mathrm{Zn}^{2+}$-dye label reveals STIM1 surface exposure. Proc Natl Acad Sci USA 104:3693-3697

14. Heo WD, Inoue T, Park WS, Kim ML, Park BO, Wandless TJ, Meyer T (2006) PI(3,4,5)P3 and PI(4,5)P2 lipids target proteins with polybasic clusters to the plasma membrane. Science 314:1458-1461

15. Hofer AM, Fasolato C, Pozzan T (1998) Capacitative $\mathrm{Ca}^{2+}$ entry is closely linked to the filling state of internal $\mathrm{Ca}^{2+}$ stores: a study using simultaneous measurements of ICRAC and intraluminal $\left[\mathrm{Ca}^{2+}\right]$. J Cell Biol 140:325-334

16. Hoth M, Fanger CM, Lewis RS (1997) Mitochondrial regulation of store-operated calcium signaling in T lymphocytes. J Cell Biol 137:633-648

17. Hoth M, Penner R (1992) Depletion of intracellular calcium stores activates a calcium current in mast cells. Nature 355:353-356

18. Irvine RF (1990) 'Quantal' $\mathrm{Ca}^{2+}$ release and the control of $\mathrm{Ca}^{2+}$ entry by inositol phosphates - a possible mechanism. FEBS Lett 263:5-9

19. Liou J, Fivaz M, Inoue T, Meyer T (2007) Live-cell imaging reveals sequential oligomerization and local plasma membrane targeting of stromal interaction molecule 1 after $\mathrm{Ca}^{2+}$ store depletion. Proc Natl Acad Sci USA 104:9301-9306

20. Liou J, Kim ML, Heo WD, Jones JT, Myers JW, Ferrell JE Jr., Meyer T (2005) STIM is a $\mathrm{Ca}^{2+}$ sensor essential for $\mathrm{C}^{2}+$-storedepletion-triggered $\mathrm{Ca}^{2+}$ influx. Curr Biol 15:1235-1241

21. Luik RM, Wu MM, Buchanan J, Lewis RS (2006) The elementary unit of store-operated $\mathrm{Ca}^{2+}$ entry: local activation of CRAC channels by STIM1 at ER-plasma membrane junctions. J Cell Biol 174:815-825

22. Malli R, Frieden M, Trenker M, Graier WF (2005) The role of mitochondria for $\mathrm{Ca}^{2+}$ refilling of the endoplasmic reticulum. J Biol Chem 280:12114-12122

23. Marriott I, Mason MJ (1995) ATP depletion inhibits capacitative $\mathrm{Ca}^{2+}$ entry in rat thymic lymphocytes. Am J Physiol 269:C766C774

24. Nakanishi S, Catt KJ, Balla T (1995) A wortmannin-sensitive phosphatidylinositol 4-kinase that regulates hormone-sensitive pools of inositolphospholipids. Proc Natl Acad Sci U S A 92:5317-5321

25. Nunez L, Senovilla L, Sanz-Blasco S, Chamero P, Alonso MT, Villalobos C, Garcia-Sancho J (2007) Bioluminescence imaging of mitochondrial $\mathrm{Ca}^{2+}$ dynamics in soma and neurites of individual adult mouse sympathetic neurons. J Physiol 580:385395

26. Oritani K, Kincade PW (1996) Identification of stromal cell products that interact with pre-B cells. J Cell Biol 134:771-782

27. Palmer AE, Jin C, Reed JC, Tsien RY (2004) Bcl-2-mediated alterations in endoplasmic reticulum $\mathrm{Ca} 2+$ analyzed with an improved genetically encoded fluorescent sensor. Proc Natl Acad Sci USA 101:17404-17409

28. Parekh AB (2008) Mitochondrial regulation of store-operated CRAC channels. Cell Calcium (in press)

29. Parekh AB, Penner R (1997) Store depletion and calcium influx. Physiol Rev 77:901-930

30. Parekh AB, Putney JW Jr (2005) Store-operated calcium channels. Physiol Rev 85:757-810

31. Park MK, Ashby MC, Erdemli G, Petersen OH, Tepikin AV (2001) Perinuclear, perigranular and sub-plasmalemmal mitochon- dria have distinct functions in the regulation of cellular calcium transport. EMBO J 20:1863-1874

32. Parker NJ, Begley CG, Smith PJ, Fox RM (1996) Molecular cloning of a novel human gene (D11S4896E) at chromosomal region 11 p15.5. Genomics 37:253-256

33. Pedersen SF, Owsianik G, Nilius B (2005) TRP channels: an overview. Cell Calcium 38:233-252

34. Petersen $\mathrm{OH}$, Tepikin AV (2008) Polarized calcium signaling in exocrine gland cells. Annu Rev Physiol 70:273-299

35. Prakriya M, Feske S, Gwack Y, Srikanth S, Rao A, Hogan PG (2006) Orail is an essential pore subunit of the CRAC channel. Nature 443:230-233

36. Putney JW Jr (1986) A model for receptor-regulated calcium entry. Cell Calcium 7:1-12

37. Putney JW Jr (2007) Recent breakthroughs in the molecular mechanism of capacitative calcium entry (with thoughts on how we got here). Cell Calcium 42:103-110

38. Roos J, DiGregorio PJ, Yeromin AV, Ohlsen K, Lioudyno M, Zhang S, Safrina O, Kozak JA, Wagner SL, Cahalan MD, Velicelebi G, Stauderman KA (2005) STIM1, an essential and conserved component of store-operated $\mathrm{Ca}^{2+}$ channel function. $\mathrm{J}$ Cell Biol 169:435-445

39. Sabbioni S, Barbanti-Brodano G, Croce CM, Negrini M (1997) GOK: a gene at 11p15 involved in rhabdomyosarcoma and rhabdoid tumor development. Cancer Res 57:4493-4497

40. Smyth JT, Dehaven WI, Bird GS, Putney JW Jr (2007) Role of the microtubule cytoskeleton in the function of the store-operated $\mathrm{Ca}^{2}$ + channel activator STIM1. J Cell Sci 120:3762-3771

41. Taylor CW, Moneer Z (2004) Regulation of capacitative and noncapacitative $\mathrm{Ca}^{2+}$ entry in A7r5 vascular smooth muscle cells. Biol Res 37:641-645

42. Varnai P, Thyagarajan B, Rohacs T, Balla T (2006) Rapidly inducible changes in phosphatidylinositol 4,5-bisphosphate levels influence multiple regulatory functions of the lipid in intact living cells. J Cell Biol 175:377-382

43. Varnai P, Toth B, Toth DJ, Hunyady L, Balla T (2007) Visualization and manipulation of plasma membrane-endoplasmic reticulum contact sites indicates the presence of additional molecular components within the STIM1-Orail complex. J Biol Chem 282:29678-29690

44. Vig M, Peinelt C, Beck A, Koomoa DL, Rabah D, KoblanHuberson M, Kraft S, Turner H, Fleig A, Penner R, Kinet JP (2006) CRACM1 is a plasma membrane protein essential for store-operated $\mathrm{Ca}^{2+}$ entry. Science 312:1220-1223

45. Williams RT, Manji SS, Parker NJ, Hancock MS, Van SL, Eid JP, Senior PV, Kazenwadel JS, Shandala T, Saint R, Smith PJ, Dziadek MA (2001) Identification and characterization of the STIM (stromal interaction molecule) gene family: coding for a novel class of transmembrane proteins. Biochem J 357:673685

46. Wu MM, Buchanan J, Luik RM, Lewis RS (2006) $\mathrm{Ca}^{2+}$ store depletion causes STIM1 to accumulate in ER regions closely associated with the plasma membrane. J Cell Biol 174:803-813

47. Yuan JP, Zeng W, Huang GN, Worley PF, Muallem S (2007) STIM1 heteromultimerizes TRPC channels to determine their function as store-operated channels. Nat Cell Biol 9:636-645

48. Zhang SL, Yeromin AV, Zhang XH, Yu Y, Safrina O, Penna A, Roos J, Stauderman KA, Cahalan MD (2006) Genome-wide RNAi screen of $\mathrm{Ca}(2+)$ influx identifies genes that regulate $\mathrm{Ca}(2+)$ release-activated $\mathrm{Ca}(2+)$ channel activity. Proc Natl Acad Sci USA 103:9357-9362

49. Zweifach A, Lewis RS (1995) Rapid inactivation of depletionactivated calcium current (ICRAC) due to local calcium feedback. J Gen Physiol 105:209-226 